\title{
Right laparoscopic adrenalectomy vs. left laparoscopic adrenalectomy: a systematic review and meta-analysis
}

Yaxuan Wang, Zhan Yang, Xueliang Chang, Jingdong Li, Yanping Zhang, Zhihai Teng, Zhenwei Han

Department of Urology, The Second Hospital of Hebei Medical University, Hebei, China

Videosurgery Miniinv 2022; 17 (1): 9-19

DOI: https://doi.org/10.5114/wiitm.2021.108212

\begin{abstract}
Introduction: Due to more complex anatomical features, right laparoscopic adrenalectomy (RLA) could be more challenging than left laparoscopic adrenalectomy (LLA). However, this opinion remains elusive.

Aim: To evaluate the perioperative and postoperative outcomes of RLA versus $L L A$.

Material and methods: A systematic literature research of the PubMed, Ovid, Scopus databases (up to March 2021) and citation lists were performed to identify eligible studies. All studies comparing RLA versus LLA were included. Data were analysed using RevMan 5.4 software.

Results: Overall, 5 studies including 780 patients (RLA 361; LLA 419) were included. The operative time was similar in both groups (WMD -9.38 min, 95\% Cl:-21.04 to 2.28; $p=0.11$ ). Compared with LLA, RLA showed greater volume of estimated blood loss (EBL) (WMD $13.82 \mathrm{ml}, 95 \% \mathrm{Cl}: 3.77,23.88 ; p=0.007)$ and higher conversion rate $(O R=3.45$, 95\% Cl: 1.12 to 10.57; $p=0.03)$. RLA had comparable complications (OR =0.88, 95\% Cl: 0.44 to $1.76 ; p=0.71)$, Clavien Dindo score $\geq 3$ complications ( $O R=0.38,95 \% \mathrm{Cl}: 0.09$ to $1.65 ; p=0.20)$, and length of hospital stay (WMD -0.07 days, $95 \% \mathrm{Cl}:-0.35$ to $0.21 ; p=0.61)$. The transperitoneal approach analysis showed consistent results. Conclusions: RLA is associated with a higher risk of bleeding and higher conversion rate.
\end{abstract}

Key words: laparoscopic adrenalectomy, right side, left side, meta-analysis.

\section{Introduction}

Laparoscopic adrenalectomy (LA) was first reported by Gagner in 1992 [1]. With the development of instruments and skills, LA has improved to give better cosmetic results, less blood loss, and shorter length of hospital stay [2, 3]. Therefore, LA has been the gold standard surgical treatment for benign adrenal lesions $[4,5]$. The right adrenal gland is partially retrocaval and drains directly to the inferior vena cava through a short central vein $[6,7]$. Due to the anatomical features, right laparoscopic adrenalectomy (RLA) could be more challenging than left laparoscopic adrenalectomy (LLA) [6, 8]. However, other studies found the opposite results [7, 9].
Therefore, the perioperative and postoperative outcomes of RLA versus LLA are still controversial. Indeed, it is necessary to analyse the current evidence and draw objective conclusions. The purpose of this study is to perform a meta-analysis to evaluate the challenging factors of RLA versus LLA.

\section{Aim}

The aim of this study is to compare RLA with LLA and determine whether there are significant differences in terms of operative time, estimated blood loss (EBL), conversion, complications, and length of hospital stay. 


\section{Material and methods}

\section{Search strategy}

We conducted a comprehensive electronic literature search on the PubMed, Ovid, Scopus databases (up to March 2021) and reference lists to identify eligible studies comparing RLA and LLA for adrenal lesions. The search strategy was "(laparoscopic adrenalectomy) and (left OR left-sided) AND (right OR right-sided)". The Preferred Reporting Items for Systematic Reviews and Meta-analysis (PRISMA) criteria were used for article selection (Figure 1). Two investigators (YW and ZY) independently screened all citations and abstracts to identify potentially eligible

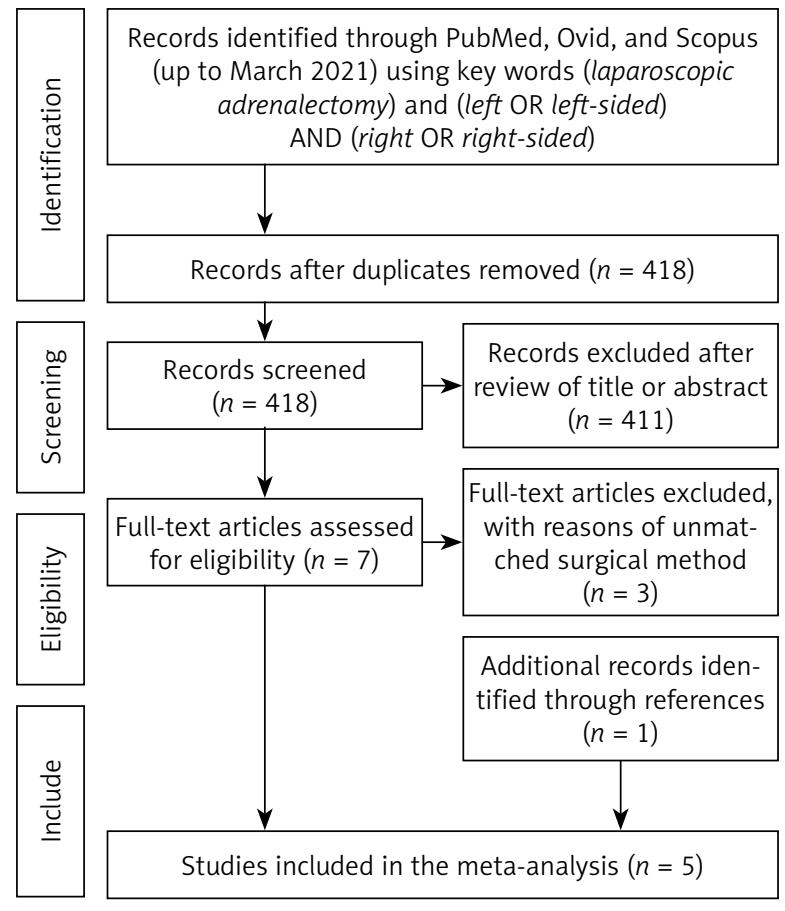

Figure 1. PRISMA flow diagram of the search strategy and identification of the included studies studies. Relevant references were also checked for additional eligible articles.

\section{Inclusion and exclusion criteria}

Inclusion criteria: (1) original studies comparing RLA to LLA; (2) written in English laguage for adult patients. Exclusion criteria: (1) children's studies; (2) non-English laguage articles; (3) studies without primary or sufficient data (i.e. reviews, commentaries, conference abstracts).

\section{Data extraction}

Two investigators (XC and ZT) independently extracted data using a predefined data extraction form, including demographic characteristics (age, gender, body mass index (BMI), tumour size), peri-operative outcomes (operative time, EBL, and conversion), and post-operative outcomes (complications, Clavien-Dindo score $\geq 3$ complications, and length of hospital stay). Any discrepancy was resolved in consultation with YW.

\section{Quality assessment}

Two investigators ( $\mathrm{L}$ and $\mathrm{YZ}$ ) independently evaluated the evidence level of included studies according to the Oxford Centre for Evidence-based Medicine (Table I).

\section{Statistical analysis}

A meta-analysis was conducted using Cochrane Collaboration's Review Manager (RevMan) 5.4 software (Cochrane Collaboration, Oxford, UK). For continuous variables, the weighted mean difference (WMD) was used with 95\% confidence intervals (Cl). For dichotomous variables, the odds ratio (OR) was calculated with $95 \% \mathrm{Cl}$. For studies that only reported medians and ranges, a validated mathematical model

Table I. Basic characteristics of included studies in this meta-analysis

\begin{tabular}{|c|c|c|c|c|c|}
\hline Study & Period & Approach & Region & Right/Left (n) & LE \\
\hline Gunseren 2019 [6] & 2006-2017 & Transperitoneal & Turkey & $135 / 137$ & 4 \\
\hline Cianci 2016 [7] & 2010-2015 & Transperitoneal & Italy & $21 / 21$ & 4 \\
\hline Chiang 2013-R [8] & 2000-2011 & Retroperitoneal & China & $31 / 51$ & 4 \\
\hline Chiang 2013 [8] & 2000-2011 & Transperitoneal & China & $24 / 21$ & 4 \\
\hline Rieder 2010 [9] & 1998-2007 & Transperitoneal & USA & $54 / 109$ & 4 \\
\hline Kokorak 2016 [11] & 2006-2016 & Transperitoneal & Slovak & $96 / 80$ & 4 \\
\hline
\end{tabular}

LE - level of evidence according to the Oxford Centre for Evidence-based Medicine; Chiang 2013, $R$ - retroperitoneal approach data from Chiang 2013. 


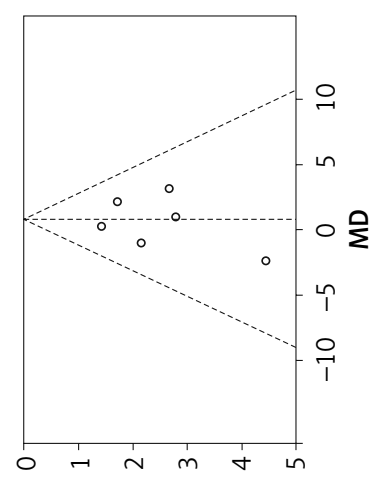

$(\mathrm{aW}) \exists \mathrm{S}$

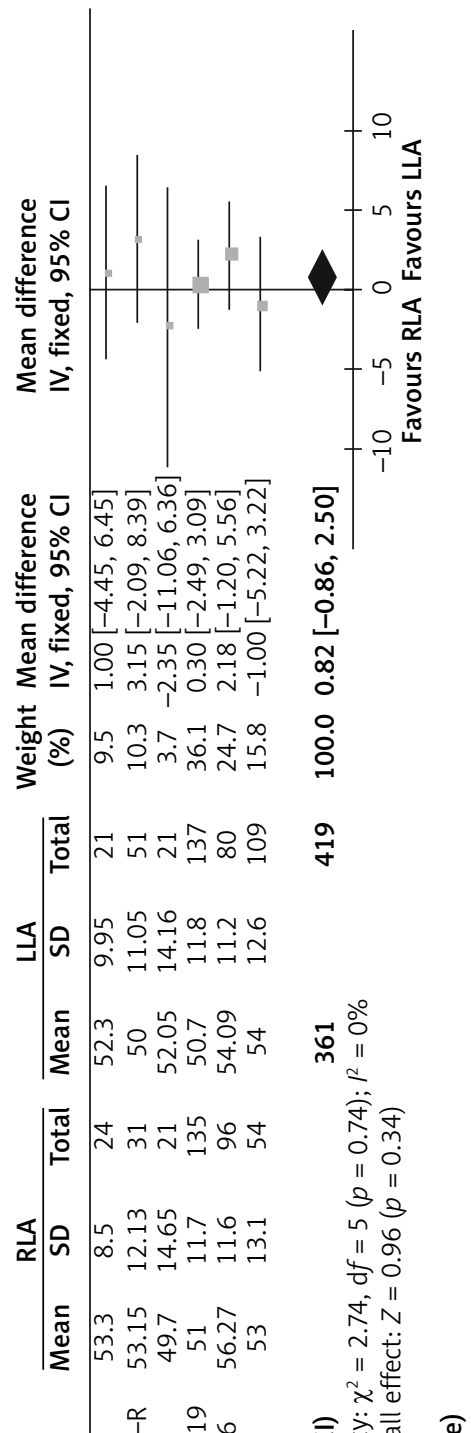

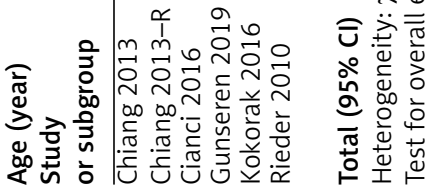
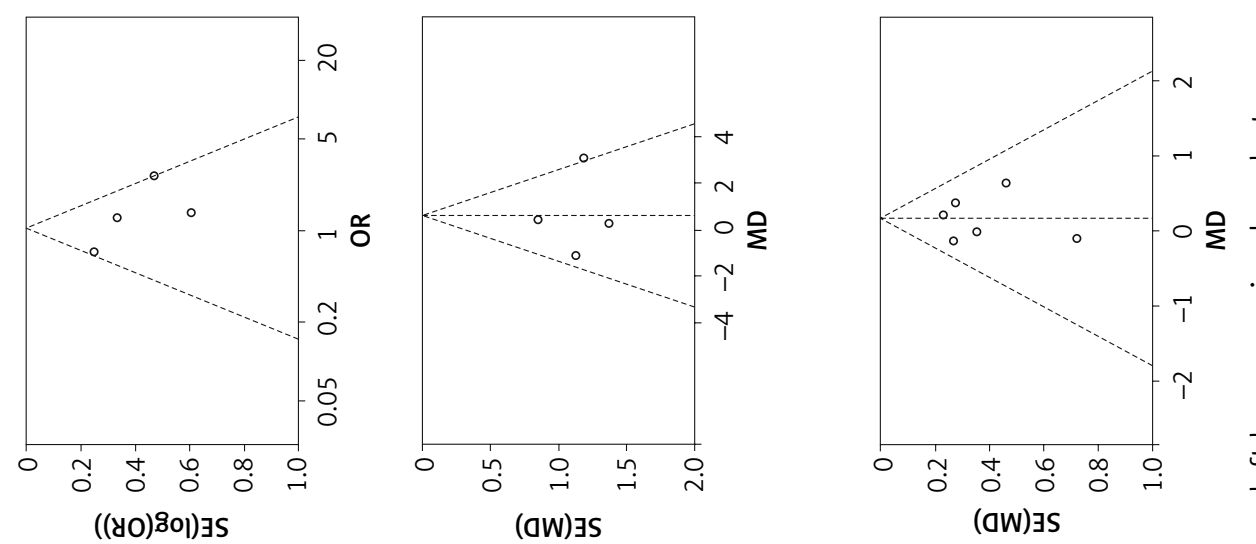

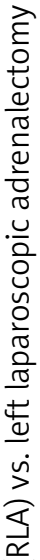
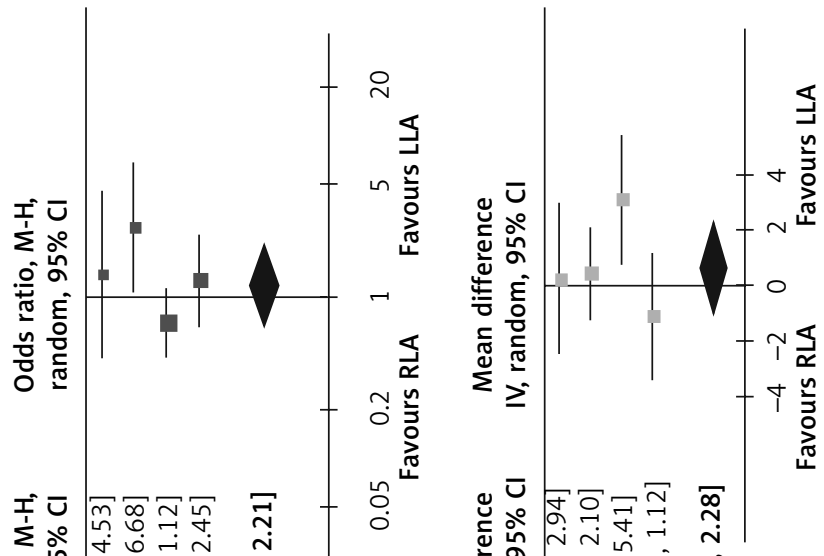

岕 品

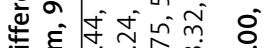

要要

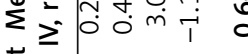

葶@

悹

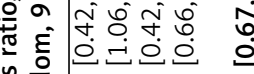

氕 듕

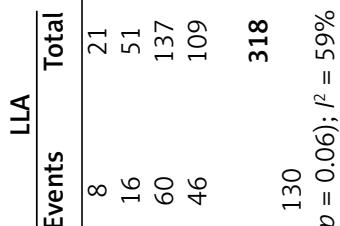

|ㅠㅠㅇ

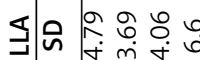

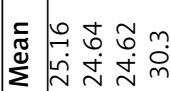

|

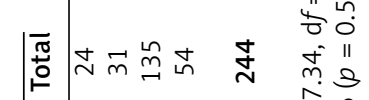

$\underset{\square}{\propto}$

埒

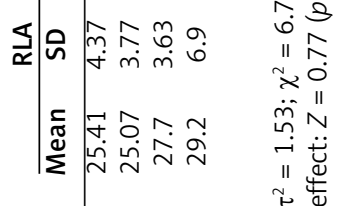

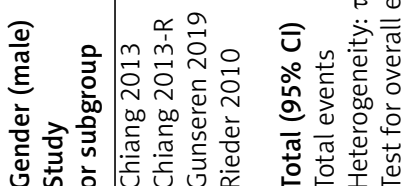

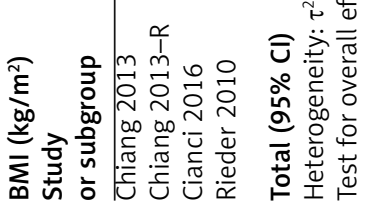

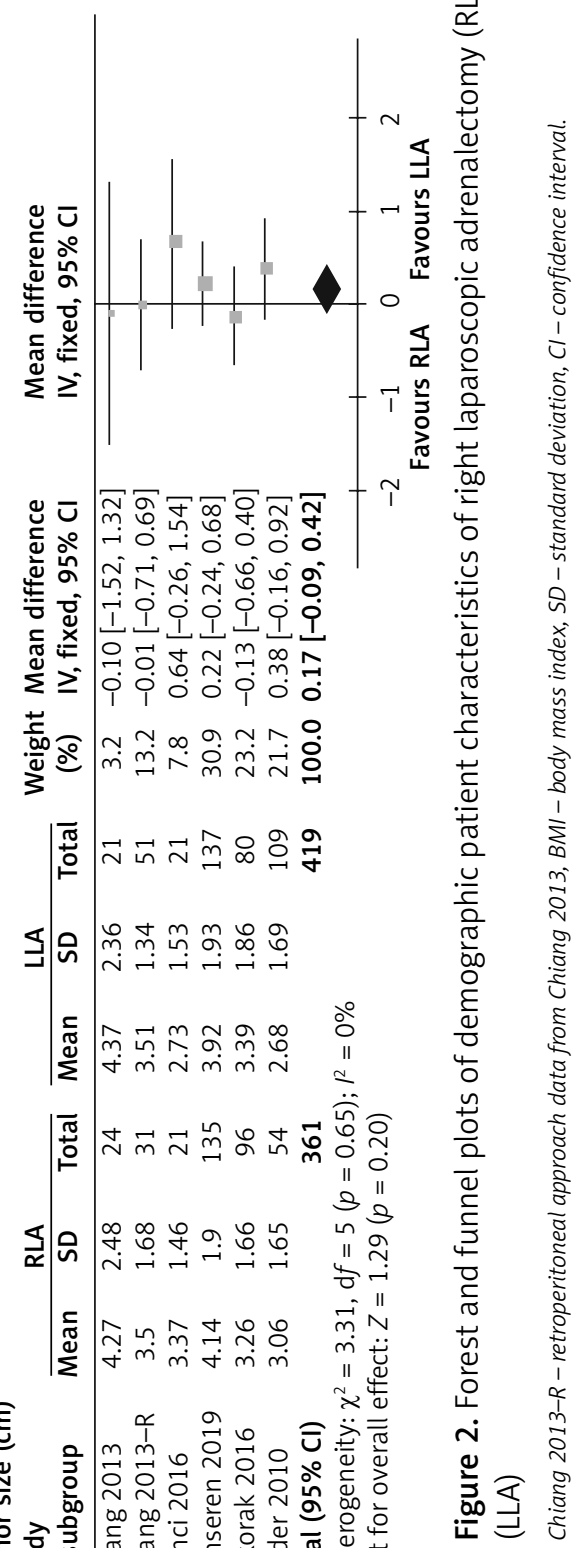


reported by Hozo et al. was used to convert the median (range) to the mean (standard deviation) [10]. Statistical heterogeneity was defined based on the Cochrane Q $p$-value and $l^{2}$ statistic. If $p>0.1$ or $l^{2}<50 \%$, a fixed-effects model was used. While, if $p<0.1$ or $1^{2}>50 \%$, a random-effects model was used. A $p$-value $<0.05$ was considered statistically significant. Funnel plots were examined to evaluate publication bias.

\section{Results}

Overall, 5 studies including 780 patients (RLA 361; LLA 419) were included in this analysis (Figure 1) [6-11]. Table I shows the basic characteristics and quality assessment of the included studies.

There was no significant difference in age (WMD 0.82 years, $95 \% \mathrm{Cl}$ : -0.86 to $2.50 ; p=0.34)$, proportion of male patients $(O R=1.22,95 \% \mathrm{Cl}: 0.67$ to $2.21 ; p=0.51)$, BMI (WMD $0.64 \mathrm{~kg} / \mathrm{m}^{2}, 95 \% \mathrm{Cl}:-1.00$ to $2.28 ; p=0.44$ ), and tumour size (WMD $0.17 \mathrm{~cm}$, 95\% Cl: -0.09 to $0.42 ; p=0.20$ ) (Figure 2).

Four studies including 653 patients (RLA 306; LLA $347)$ reported operative time $[6,7,9,11]$. There was no significant difference in operative time (WMD $-9.38 \mathrm{~min}, 95 \% \mathrm{Cl}:-21.04$ to $2.28 ; p=0.11$ ). Three studies including 477 patients (RLA 210; LLA 267) reported $\mathrm{EBL}[6,7,9]$. Meta-analysis of these studies showed more EBL for RLA (WMD $13.82 \mathrm{ml}, 95 \% \mathrm{Cl}$ : $3.77,23.88 ; p=0.007$ ). Four studies including 508 patients (RLA 226; LLA 282) reported the conversion rate [7-11]. RLA was associated with higher conversion rate compared with $\operatorname{LLA}(\mathrm{OR}=3.45,95 \% \mathrm{Cl}$ : 1.12 to $10.57 ; p=0.03$ ) (Figure 3).

Four studies including 508 patients (RLA 226; LLA 282) reported complications [7-9, 11]. Three studies including 345 patients (RLA 172; LLA 173) reported Clavien-Dindo score $\geq 3$ complications [7, 8, 11]. Five studies including 780 patients (RLA 361; LLA 419) reported the length of hospital stay [6-9, 11]. Meta-analysis of these studies showed that RLA had similar rate of complications (OR $=0.88,95 \% \mathrm{Cl}$ : 0.44 to $1.76 ; p=0.71)$, rate of Clavien-Dindo score $\geq 3$ complications $(\mathrm{OR}=0.38,95 \% \mathrm{Cl}$ : 0.09 to 1.65 ; $p=0.20$ ), and length of hospital stay (WMD -0.07 days, $95 \% \mathrm{Cl}:-0.35$ to $0.21 ; p=0.61$ ) (Figure 4).

Most of the studies compared RLA versus LLA via transperitoneal approach, and only 1 study reported retroperitoneal results. This could lead to bias. Therefore, we analysed the transperitoneal approach data to reduce heterogeneity.
There was no significant difference in age (WMD 0.55 years, $95 \% \mathrm{Cl}:-1.22$ to $2.32 ; p=0.54$ ), proportion of male patients (OR $=2.49,95 \% \mathrm{Cl}: 0.36$ to $17.27 ; p=0.35$ ), $\mathrm{BMI}$ (WMD $0.74 \mathrm{~kg} / \mathrm{m}^{2}, 95 \% \mathrm{Cl}$ : -1.79 to $3.27 ; p=0.57$ ), and tumour size (WMD $0.19 \mathrm{~cm}, 95 \% \mathrm{Cl}:-0.08$ to $0.46 ; p=0.16$ ) (Figure 5).

Four studies including 653 patients (RLA 306; LLA $347)$ reported operative time $[6,7,9,11]$. There was no significant difference in operative time (WMD $-9.38 \mathrm{~min}, 95 \% \mathrm{Cl}$ : -21.04 to $2.28 ; p=0.11$ ). Three studies including 477 patients (RLA 210; LLA 267) reported $\mathrm{EBL}[6,7,9]$. Meta-analysis of these studies showed more EBL for RLA (WMD $13.82 \mathrm{ml}$, 95\% Cl: $3.77,23.88 ; p=0.007$ ). Four studies including 426 patients (RLA 195; LLA 231) reported the conversion rate $[7-9,11]$. RLA was associated with higher conversion rate compared with $\mathrm{LLA}(\mathrm{OR}=3.26,95 \% \mathrm{Cl}$ : 0.99 to $10.80 ; p=0.05$ ) (Figure 6 ).

Four studies including 426 patients (RLA 195; LLA 231) reported the complications [7-9, 11]. Three studies including 263 patients (RLA 141; LLA 122) reported Clavien-Dindo score $\geq 3$ complications [7, 8, 11]. Five studies including 698 patients (RLA 330; LLA 368) reported the length of hospital stay [6-9, 11]. Meta-analysis of these studies showed similar rates of complications ( $O R=1.00,95 \% \mathrm{Cl}: 0.48$ to 2.08; $p=1.00)$, rate of Clavien-Dindo score $\geq 3$ complications ( $\mathrm{OR}=0.34,95 \% \mathrm{Cl}: 0.07$ to $1.80 ; p=0.21)$, and length of hospital stay (WMD -0.09 days, 95\% Cl: -0.37 to $0.19 ; p=0.53$ ) (Figure 7 ).

There was no significant publication bias in this study.

\section{Discussion}

In the past decade, LA has been the gold standard method for the treatment of benign adrenal lesions. Recently, Sahbaz et al. reported that LA can be safely performed on large adrenal masses without obvious perioperative and postoperative complications [12]. Because the right adrenal gland is partially retrocaval and drains directly to the inferior vena cava through a short central vein, there is an opinion that RLA is more challenging than LLA [6, $8,13]$. While, Kokorak et al. reported similar results between RLA and LLA [11]. However, some studies reported that LLA was more challenging than RLA $[7,9,14]$. Therefore, it is necessary to conduct a meta-analysis to evaluate the efficacy and safety of RLA and LLA. 

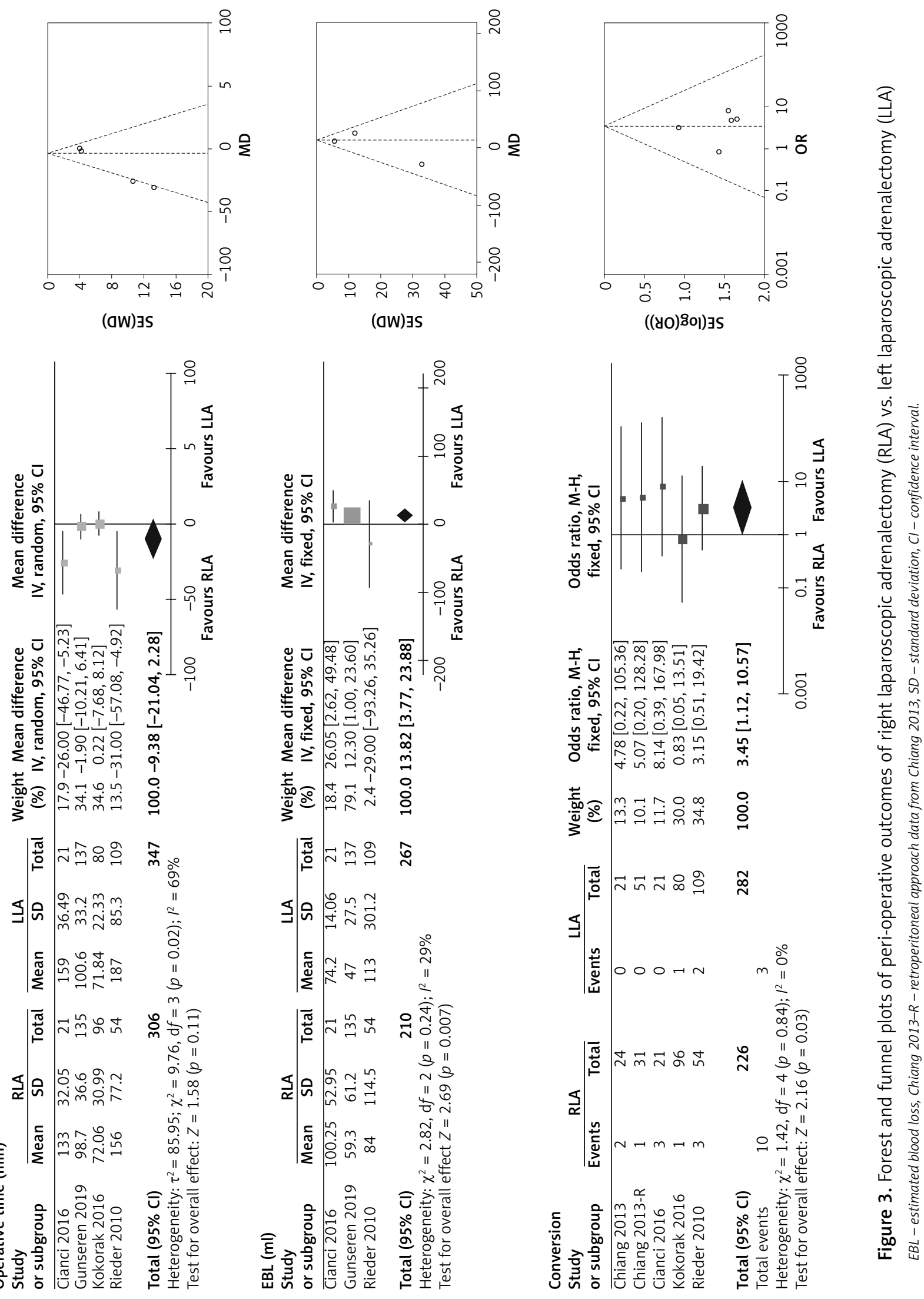


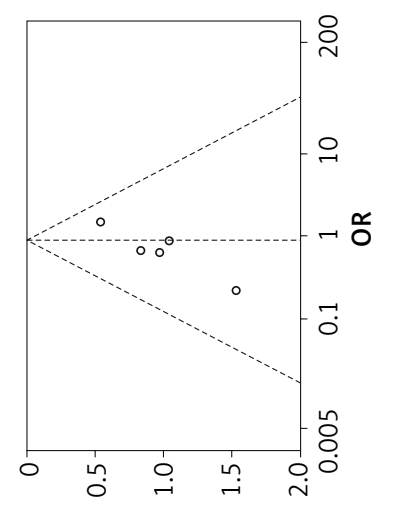

((yo)80이)ヨS

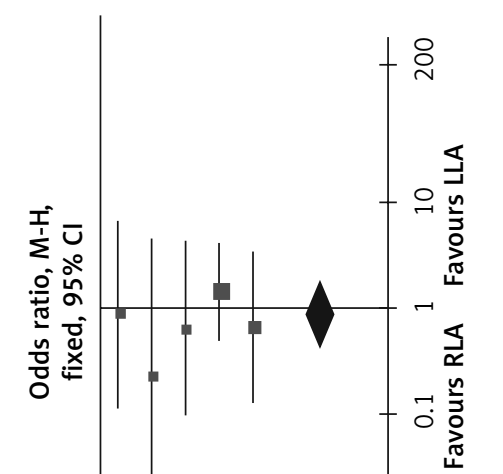

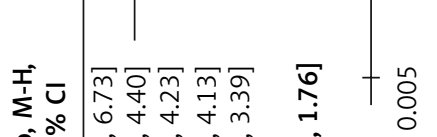

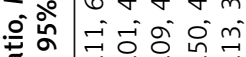

घं

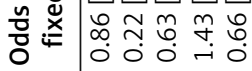

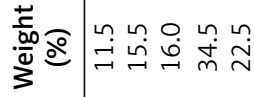

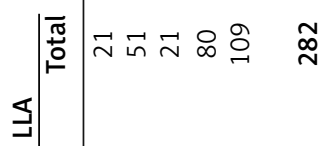

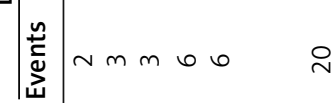

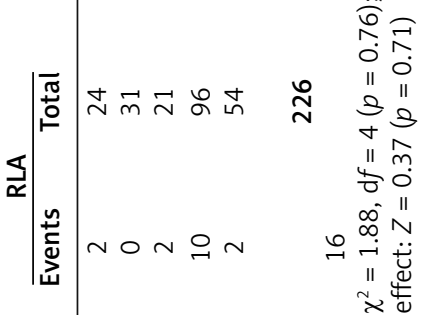

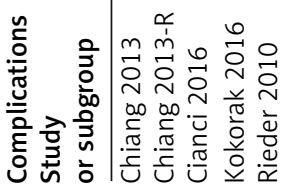

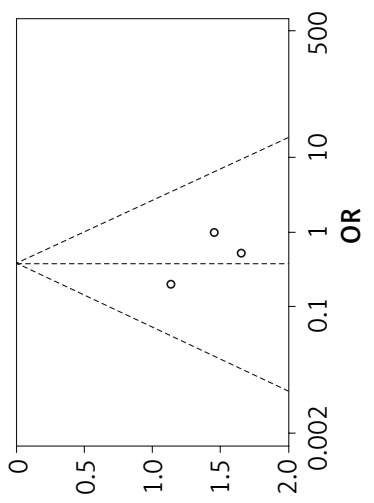

((yo)8이) $\exists S$

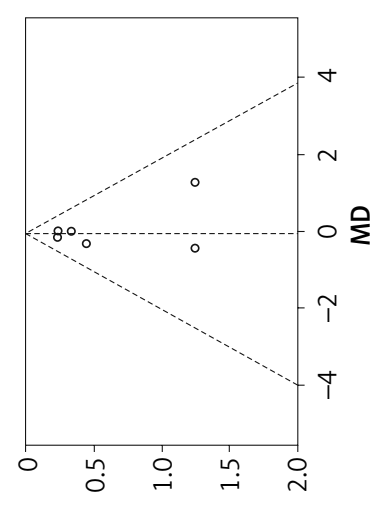

(aW) $\exists \mathrm{S}$
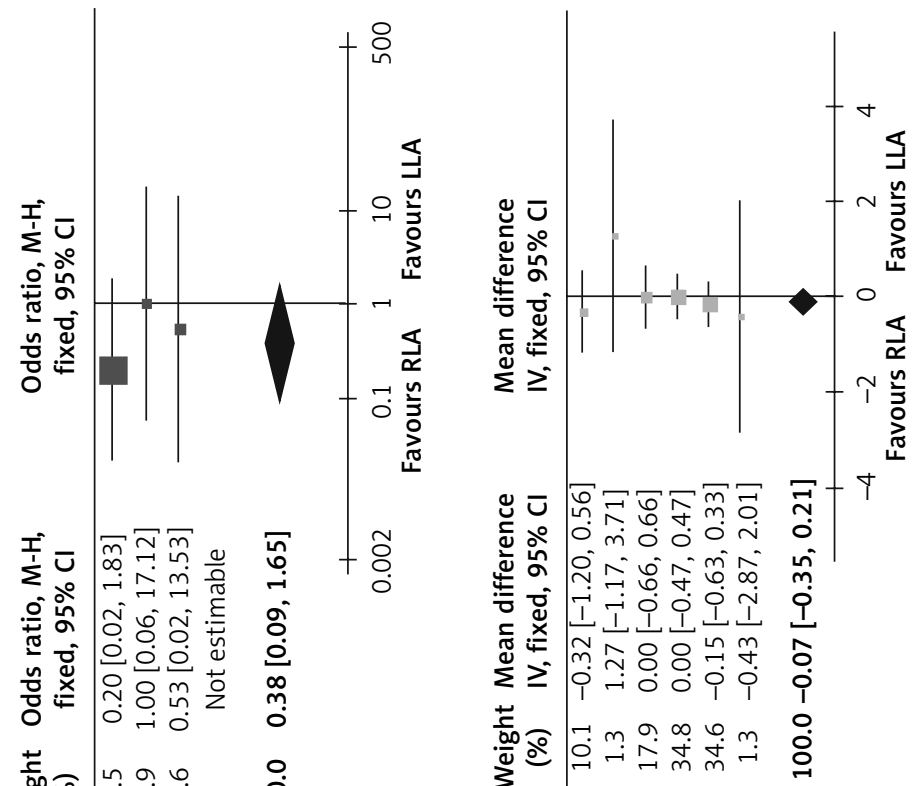

$\mid \overrightarrow{\widetilde{0}}$

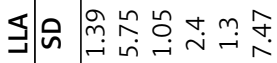

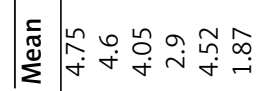



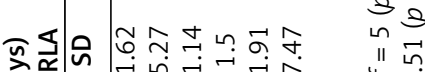

晃

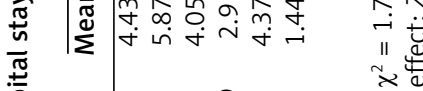



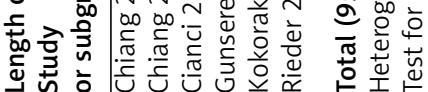




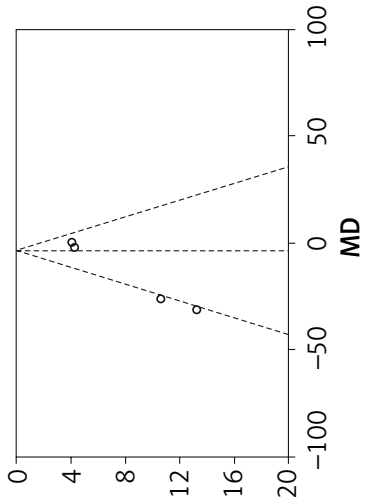

(aW) $\exists S$

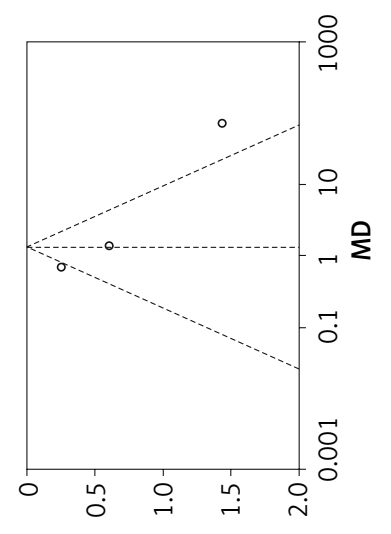

(aw) $\exists S$

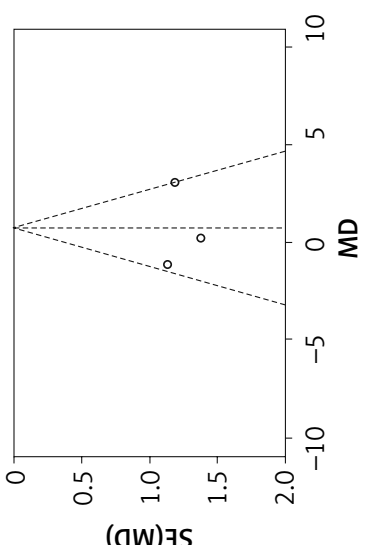

(aw) $\exists \mathrm{S}$

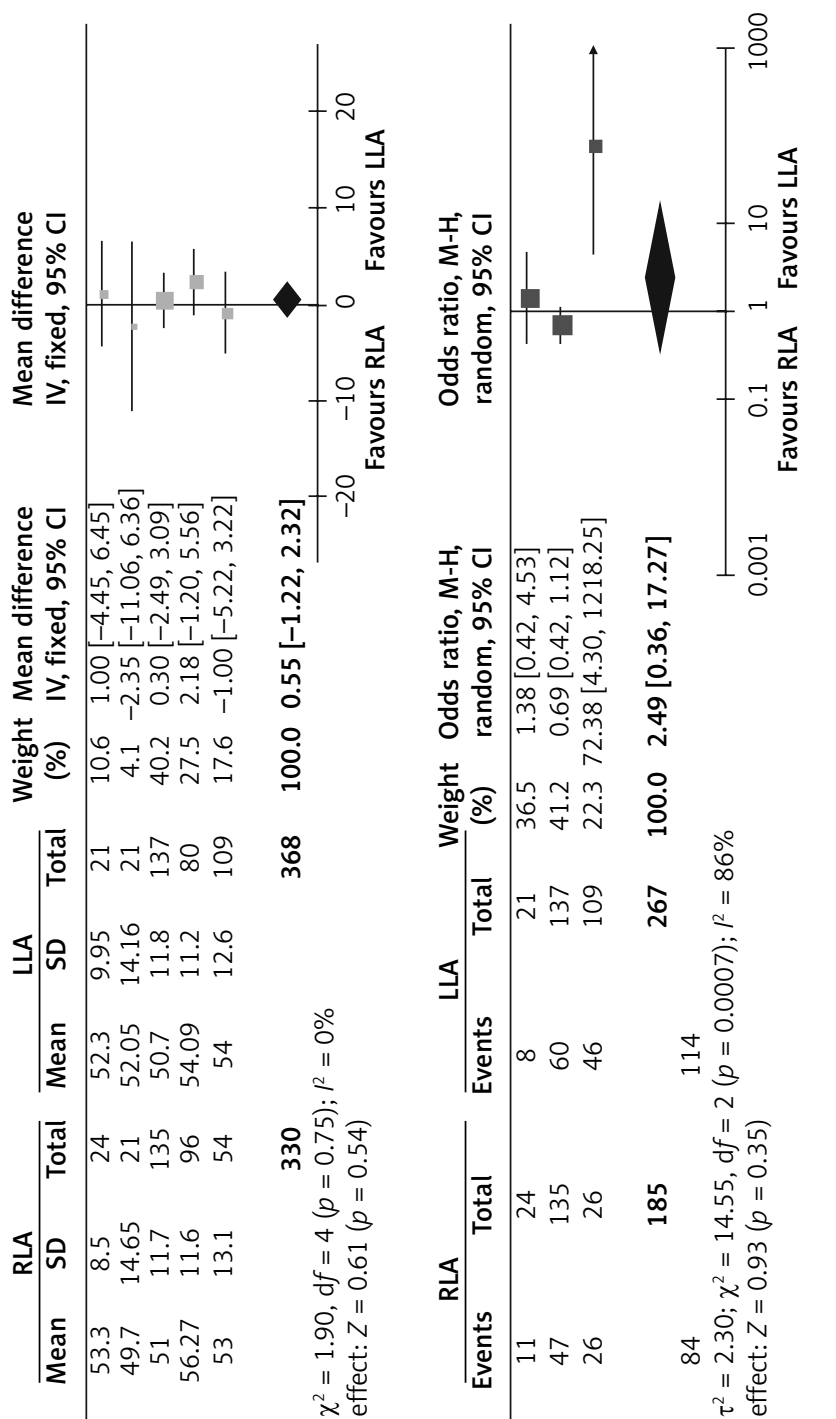

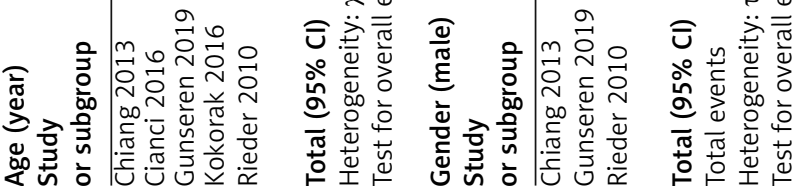

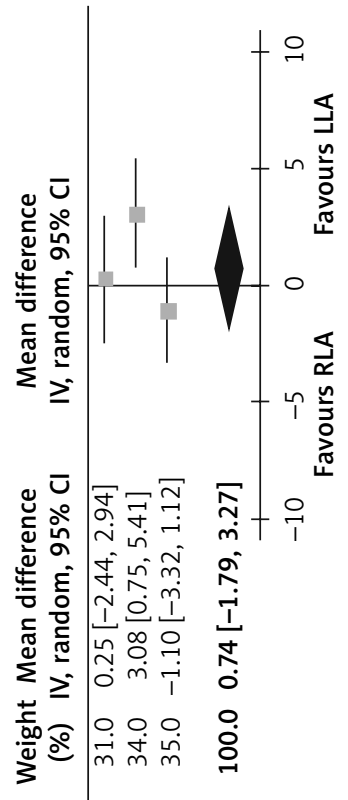

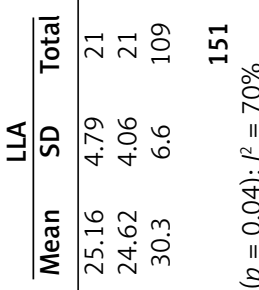

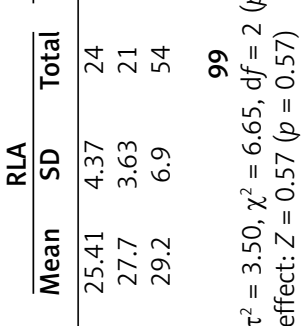

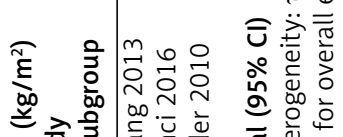

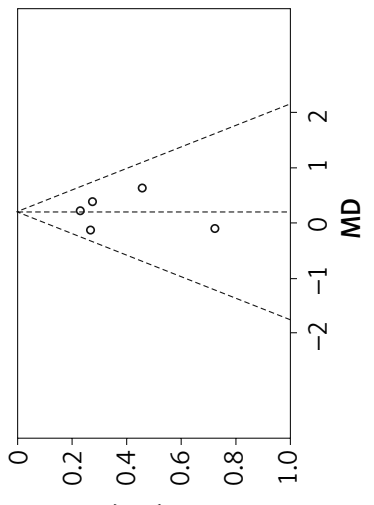

$(\mathrm{aW}) \exists \mathrm{S}$

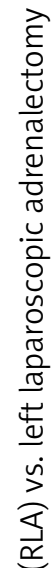

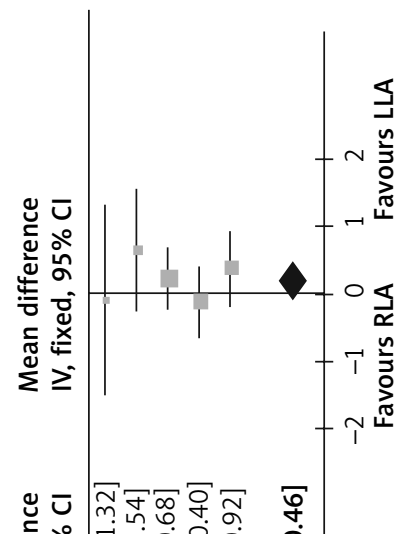

$\stackrel{\square}{\leftrightarrows}$

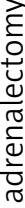
$\frac{.}{\circ}$

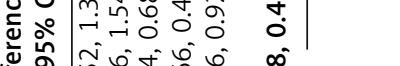

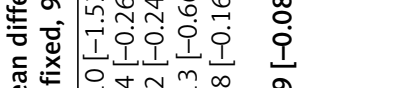

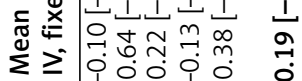

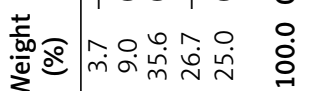

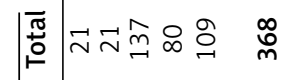

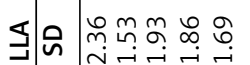

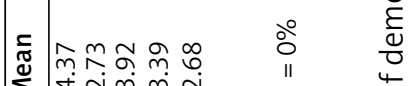

irimmina

|

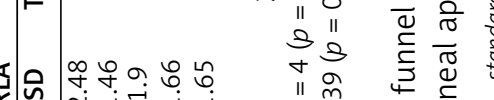

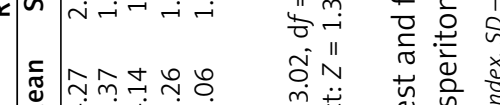

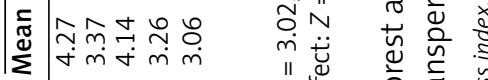

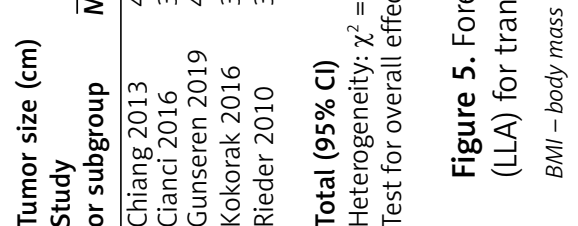



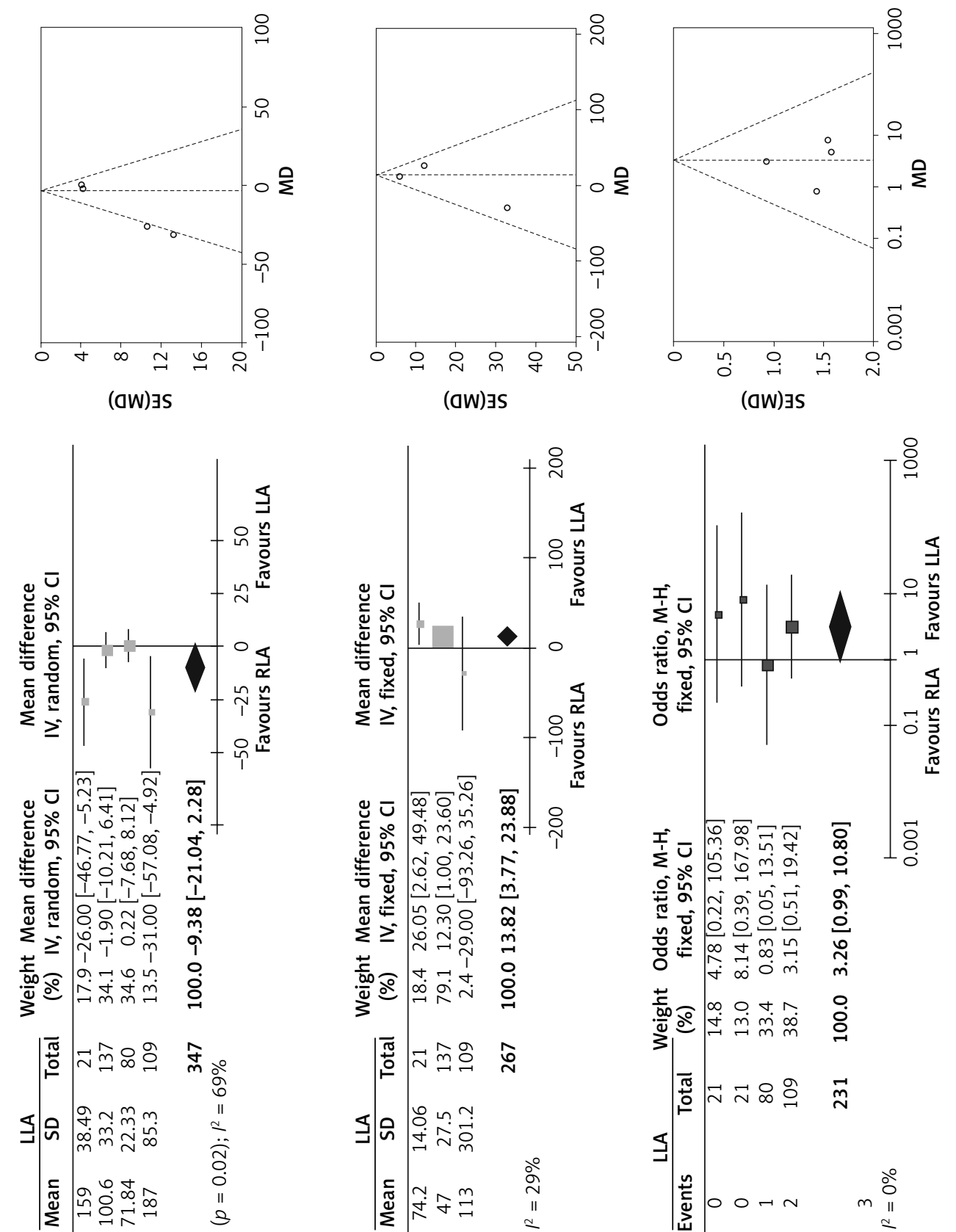

|

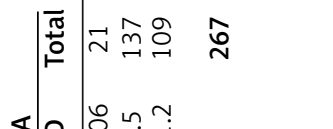

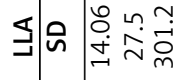

离

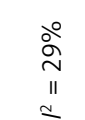

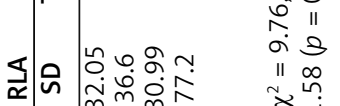

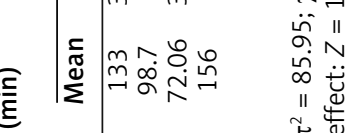

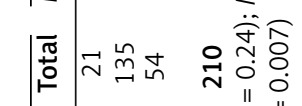

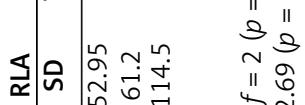

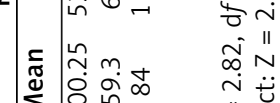

丞

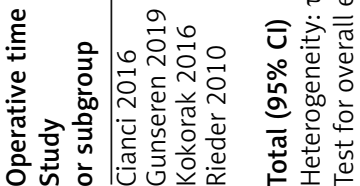

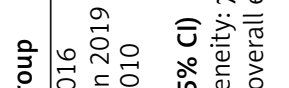

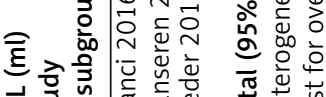

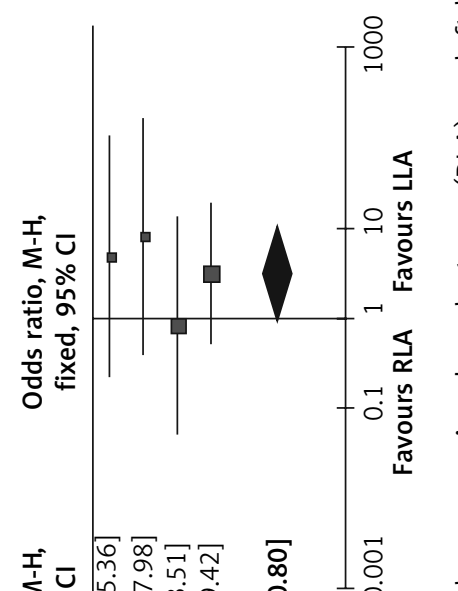

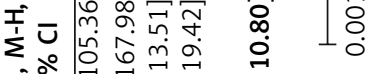

ㅇํำ



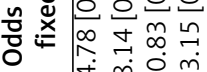

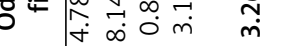

范苛

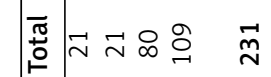

$\unlhd$

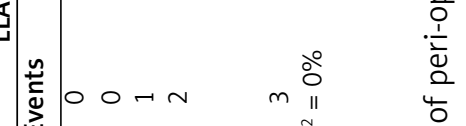

这 


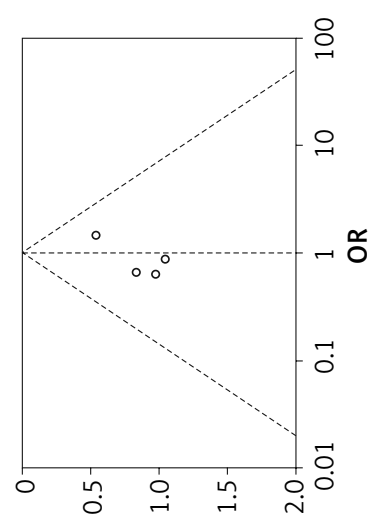

((yo)8이) $\exists S$

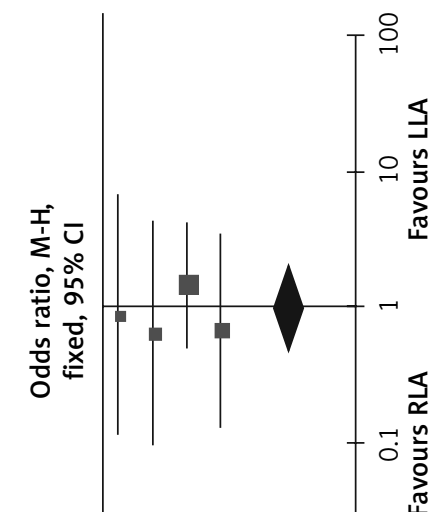

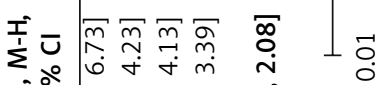

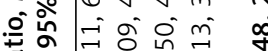

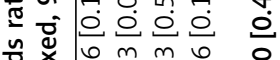

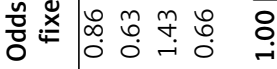

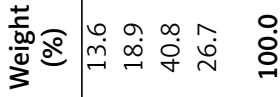

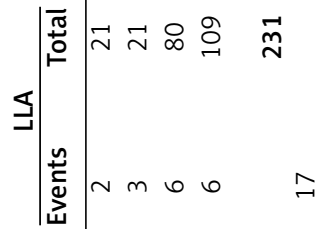

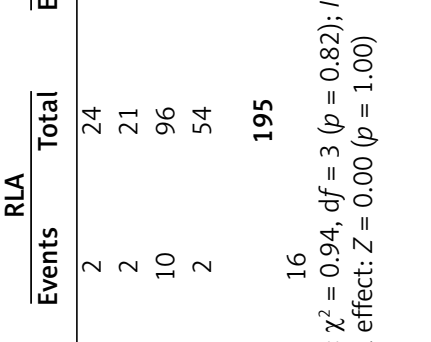

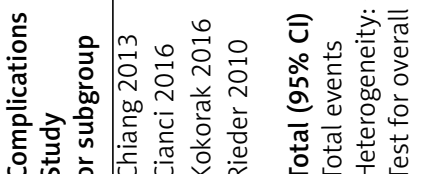

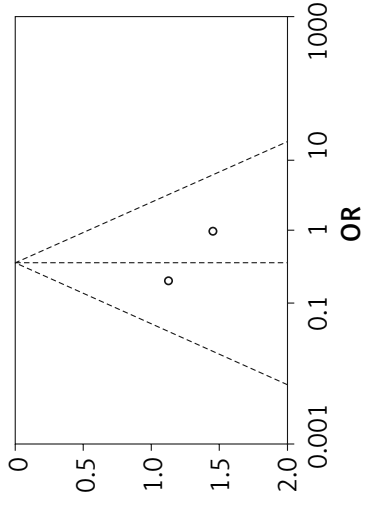

((yo)이이) $\exists S$

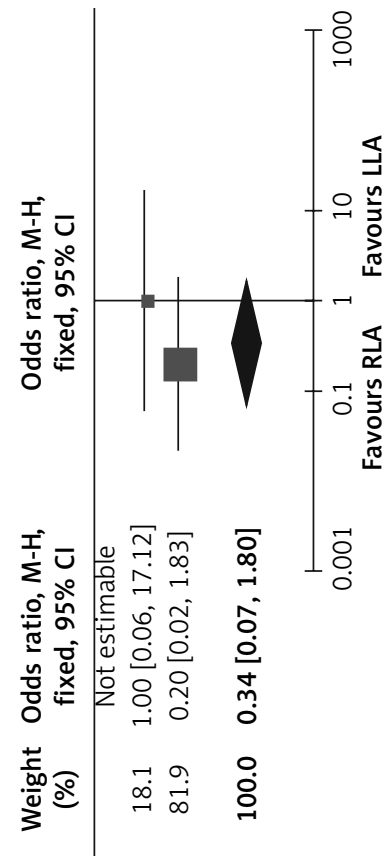

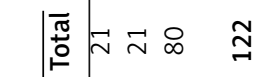

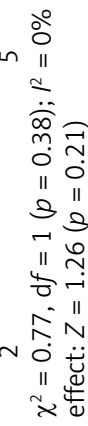

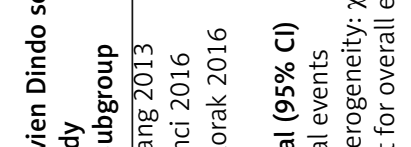

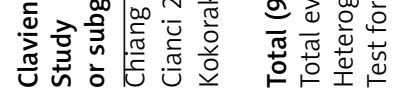

竞

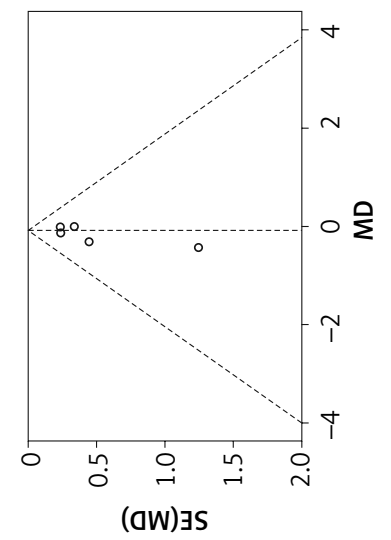

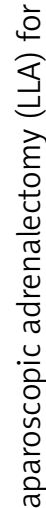

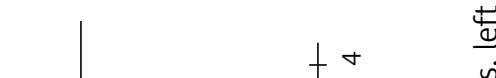

$>$

$\stackrel{\rightleftarrows}{\simeq}$

हิ

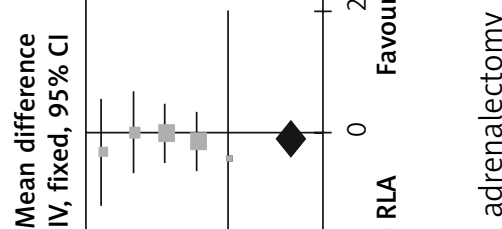

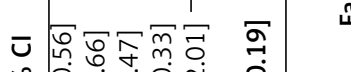

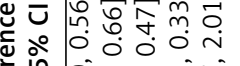

屯ूँ

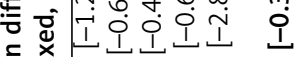

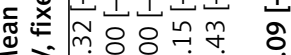

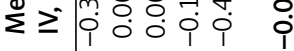

蒿

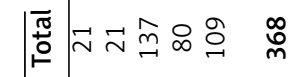

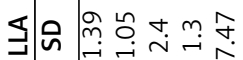

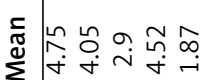

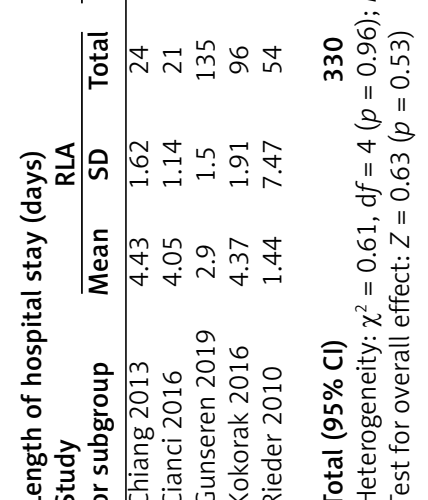


In our meta-analysis, patients treated with RLA and LLA were similar in age, gender, BMI, and tumour size. After omitting the only retroperitoneal approach data, the results were consistent. These reflected the homogeneity of the included studies.

The meta-analysis of our study showed comparable operative time. RLA showed more EBL and higher conversion rate. The transperitoneal approach data showed the same results. Due to the anatomical characteristics of the right adrenal gland, RLA should be riskier. Our results also supported this theory. However, some studies have emphasized that LLA via transperitoneal approach was more complex for a variety of reasons. First, it is difficult to dissect the tail of the pancreas for better exposure of the left adrenal gland. Varkarakis et al. reported an $8 \%$ rate of pancreatic injury during LLA [15]. Second, mobilization of the splenic flexure of the colon is required for a better exposure of the left adrenal gland. Anatomical variations of the spleen are very common, which make the dissection more complicated. However, the retraction of the liver is more simple on the right side [7]. Third, the dissection of the left renal hilum for vascular control of the adrenal vein is more complicated. All these reasons indicate that the procedure on the left is more complex than the procedure on the right. Nonetheless, the left adrenal gland anatomy is more complex. An experienced surgeon can quickly complete renal hilus dissection and mobilization of the spleen and splenic colonic flexure without any problems [6]. This can also be concluded from the similarity of operative time. However, even for experienced surgeons, there was a greater possibility of bleeding from the right side. Although the RLA group had more $\mathrm{EBL}$, the mean EBL was approximate $100 \mathrm{ml}$, hardly requiring any transfusion. This reflects the safety of RLA and LLA. Indeed, there were some episodes of significant bleeding possibly requiring transfusion. In this meta-analysis, Rieder et al. reported significant bleeding for LLA. Nevertheless, RLA still had more EBL than LLA. This reflects the higher overall bleeding risk of RLA [9]. In addition, the open conversion was more common on the right side $[6,13,16,17]$. These results revealed that RLA could be riskier than LLA.

Our meta-analysis showed similar complications, Clavien Dindo score $\geq 3$ complications, and length of hospital stay. In the overall perspective, there was no significant difference in postoperative results be- tween RLA and LLA. These results reflected the safety of the 2 procedures.

There are several limitations to this study. First, the retrospective nature of the included studies limited the quality of the results. Second, the surgical approach was not standardized. Third, the small sample size limited the reliability of the results. Fourth, the pathological data were not available for analysis. Fifth, the follow-up time was unclear. Multicentre randomized controlled trials are needed to further conform the results.

\section{Conclusions}

Due to greater risk of bleeding and higher risk of conversion, RLA is riskier and deserves more attention. Nevertheless, further prospective randomized studies are needed to confirm these results.

\section{Acknowledgments}

We thank Dr. Chawnshang Chang at University of Rochester Medical Centre for helping with the preparation of the manuscript.

\section{Conflict of interest}

The authors declare no conflict of interest.

\section{References}

1. Gagner M, Lacroix A, Bolte E. Laparoscopic adrenalectomy in Cushing's syndrome and pheochromocytoma. N Engl J Med 1992; 327: 1033.

2. Hallfeldt KK, Mussack T, Trupka A, et al. Laparoscopic lateral adrenalectomy versus open posterior adrenalectomy for the treatment of benign adrenal tumors. Surg Endosc 2003; 17: 264-7.

3. Puccini M, Panicucci E, Candalise V, et al. The role of laparoscopic resection of metastases to adrenal glands. Gland Surg 2017; 6: 350-4.

4. Smith CD, Weber CJ, Amerson JR. Laparoscopic adrenalectomy: new gold standard. World J Surg 1999; 23: 389-96.

5. McCauley LR, Nguyen MM. Laparoscopic radical adrenalectomy for cancer: long-term outcomes. Curr Opin Urol 2008; 18: 134-8.

6. Gunseren KO, Cicek MC, Vuruskan H, et al. Challenging risk factors for right and left laparoscopic adrenalectomy: a single centre experience with 272 cases. Int Braz J Urol 2019; 45: 747-53.

7. Cianci P, Fersini A, Tartaglia N, et al. Are there differences between the right and left laparoscopic adrenalectomy? Our experience. Ann Ital Chir 2016; 87: 242-6.

8. Chiang P, Yu C, Lee W, et al. Is right-sided laparoscopic adrenalectomy truly more challenging than left-sided? The 10-year experience of a single institute. Urol Sci 2013; 24: 117-9.

9. Rieder JM, Nisbet AA, Wuerstle MC, et al. Differences in left and right laparoscopic adrenalectomy. JSLS 2010; 14: 369-73. 
10. Hozo SP, Djulbegovic B, Hozo I. Estimating the mean and variance from the median, range, and the size of a sample. BMC Med Res Methodol 2005; 5: 13.

11. Kokorak L, Soltes M, Vladovic P, et al. Laparoscopic left and right adrenalectomy from an anterior approach - is there any difference? Outcomes in 176 consecutive patients. Videosurgery Miniinv 2016; 11: 268-73.

12. Sahbaz NA, Dural AC, Akarsu C, et al. Transperitoneal laparoscopic surgery in large adrenal masses. Videosurgery Miniinv 2020; 15: 106-11.

13. Aminsharifi A, Mohammadian R, Niroomand R, et al. Optimizing the technique of right laparoscopic adrenalectomy with a modified trocar arrangement and dynamic liver retraction: a comparative study with standard technique. Int I Surg 2013; 11: 463-6.

14. Lezoche E, Guerrieri M, Crosta F, et al. Perioperative results of 214 laparoscopic adrenalectomies by anterior transperitoneal approach. Surg Endosc 2008; 22: 522-6.

15. Varkarakis IM, Allaf ME, Bhayani SB, et al. Pancreatic injuries during laparoscopic urologic surgery. Urology 2004; 64: 1089-93.

16. Zacharias M, Haese A, Jurczok A, et al. Transperitoneal laparoscopic adrenalectomy: outline of the preoperative management, surgical approach, and outcome. Eur Urol 2006; 49: 448-59.

17. Castillo OA, Vitagliano G, Secin FP, et al. Laparoscopic adrenalectomy for adrenal masses: does size matter? Urology 2008; 71: 1138-41.

Received: 30.04.2021, accepted: 30.05.2021. 